\title{
Multi User-Based Patient Service Information System in Public Health Center
}

\author{
Geby Chintya Wiendara, Satria Abadi, M. Ilayaraja, K. Shankar, Phong Thanh Nguyen, Wahidah \\ Hashim, Andino Maseleno
}

\begin{abstract}
The patient service information system at the Gisting Public Health Center, Bahasa: Pusat Kesehatan Masyarakat (Puskesmas), is the development of an existing and computerized drug inventory system. The patient service system existing at the Gisting Public Health Center does not support the recording of data so the data recording is not well organized. The purpose of this study is to create an application and implementation of a multiuser-based patient service information system. This system will provide the result of report and information needed by the patient services administration. It is hoped that this system can be used as an experienced assistant. This application helps in making decisions and operational activities as an effort to achieve the goals to be achieved by the Public Health Center. This application system analyzes the service data at the Gisting Public Health Center. This information system application development used Visual Basic 6.0 programming and for database used SQL Server 2000.
\end{abstract}

Keywords: Multiuser, Patient Service, Information System.

\section{INTRODUCTION}

\subsection{Background}

Current technological developments have helped many people in doing their jobs easily, quickly and satisfying result [1]. One of those technologies is computer, with the development of technology, all the things are more effective and efficient [2]. For example the use of computer medicine in Indonesia, which is currently growing rapidly, so many people assume that the use of information in large organizations and companies is only possible with computer service [3]. Likewise, computer plays an important role in the development of science and technology because by computerization, all information or data needed can be presented quickly, precisely and accurately [4].

Gisting Public Health Center located in Tanggmus Regency is one of the institutions engaged in the field of health that is very supportive in the field of health service, this field also requires computer technology to get fast and

Revised Manuscript Received on July 22, 2019.

* Correspondence Author

Geby Chintya Wiendara, Department of Information Systems, STMIK Pringsewu, Lampung, Indonesia.

Satria Abadi, Department of Information Systems, STMIK Pringsewu, Lampung, Indonesia.

M. Ilayaraja, Department of Computer Science and Information Technology, Kalasalingam Academy of Research and Education, Krishnankoil, India. E-mail: ilayaraja.m@klu.ac.in

K. Shankar, Department of Computer Applications, Alagappa University, Karaikudi, India.

Phong Thanh Nguyen*, Department of Project Management, Ho Chi Minh City Open University, Vietnam. E-mail: phong.nt@ou.edu.vn

Wahidah Hashim, Institute of Informatics and Computing Energy, Universiti Tenaga Nasional, Malaysia.

Andino Maseleno, Institute of Informatics and Computing Energy, Universiti Tenaga Nasional, Malaysia. accurate information in developing information especially in Patient Service located in Gisting District and the local area which is still included in the Tanggamus Regency

The system that runs today is the computer, with the development of technology, all the things are more effective and efficient [5]. For example, the use of computer medicine in Indonesia is growing rapidly lately, so many people assume that the use of information in large organizations and companies is only possible with computer services [6]. Likewise, computer plays an important role in the development of science and technology because by computerization, all information or data needed be able presented quickly, precisely and accurately [7].

\subsection{Research Question}

1. How to overcome the data recording of public health center that is still using conventional method?

2. What is the action taken to improve data if there is an error during the process of data collection at the Public Health Center service?

\subsection{Objective and Benefit of the Research}

Producing a patient service data collection system on the service information system multiuser-based patients at the Gisting Public Health Center of Tanggamus Regency to ease the data collection and achievement of report that is fast, accurate, valid, effective and efficient.

In addition, the benefits are easier for administrator to carry out the drug data collection process so the error or mistake will be reduced and report produced more quickly and accurately.

\section{LITERATURE REVIEW}

\subsection{System}

There are two group of system approaches in defining system, namely approach to procedure and approach to component / element [8]. The system approach to the procedure defines the system as follows: "A system is a network of procedures that are interconnected, gathered together to carry out a certain activity or purpose" [9]. While the system approach to its component or element defines the system as follows: The system is the elements that interact with each other and are interconnected to achieve and to form one unit [10].Decision support system is a system helping in the analysis of business information [11]. 


\section{Multi User-Based Patient Service Information System in Public Health Center}

\subsection{Information}

Information is data that is processed into a form that is more useful and more meaningful for those who receive it [12]. Information is the result of data processing so that it becomes an important form for the recipient and has a usefulness as a basis for making decision that can be felt directly or indirectly in the future [13]. To directly obtain information, data is needed to be processed and the processing unit [14].

\subsection{Data Base}

Database is the most important component in the development of information system, because it becomes a place to accommodate and organize all data on the system, so it can be explored to compile information in various forms [15]. A database is a collection of interrelated data groups, the data is organized in such a way in order nothing unnecessary duplication occur, so it can be processed or explored quickly and easily to produce information [16].

\subsection{Patient}

The definition of Patient can be divided into two namely: a. Patient who receive service to stay or to be treated in a health care unit.

b. Patient who is only receive certain health service and does not stay or to be treated in health care.

\subsection{Multiuser}

The definition of Multiuser is a system or program that can run more than one $\mathrm{PC}$ or a program that will be accessed by several computers. The advantage of using a multiuser is that it can be more effective and efficient and doesn't take much time.

\subsection{Public Health Center}

The definition of Public Health Center is a public health center, a polyclinic at the district level where the community receives health service and counseling about family planning [17].

Public Health Center is a Technical Service Unit for the District / City Health Office that is responsible for organizing health development in a work area. Puskesmas is a functional health organization that is a center for community health development that also fosters community participation and provides comprehensive and integrated services to the community in its working area in form of main activities. In other words, the Public Health Center has the authority and responsibility for maintaining public health in the working area.

\subsection{Microsoft Visual Basic 6.0}

Microsoft Visual Basic 6.0 is a programming language based on GUI (Graphic user interface). It contains commands or instructions that are understood by the computer to perform certain task. This task can be carried out if there is a response from the user. The response is in form of certain event, for example selecting a button, selecting a menu and so on.

The author used Microsoft Visual Basic 6.0 because it was easy to make the program and the application of the program is applied while in college and it was very good if the application is applied in non-local public health center that still used the manual system.

\subsection{Microsoft SQL Server}

Microsoft SQL Server is a relational database management system (RDBMS) of Microsoft product. The main query language is Transact-SQL which is an implementation of SQL of the ANSI / ISO standard used by Microsoft and Sybase. SQL Server is generally used for the business world which has a small to medium-sized database, but later developed with the use of SQL Server in large database.

The author used Microsoft Sql Server because it was a database used to store databases that connected to Visual Basic 6.0 programming application for service system at the Gisting Public Health Center in Tanggamus Regency..

\section{RESEARCH METHODOLOGY}

The research method is very necessary for the perfection of the author's system [18]. Therefore, research methods are needed to obtain accurate data, as follows:

\subsection{Data Collection Method}

This research used primary data [1], data collection methods used are as follows:

\section{a. Observation}

- Observing the process of patient registration, the process of examination of patient, the process of taking drug, collecting data of the names of doctor.

\section{b. Interview}

- What is the procedure for registering patient at the Gisting Public Health Center?

- Who is involved in the patient registration process?

- Who is involved in the process of requesting and receiving drug?

\section{c. Literature Review}

Namely by looking for references [19] or theories that are needed through reference books that are related to the problem [20].

\subsection{System Analysis and Development}

\section{a. System Development Life Cycle (SDLC)}

It is a phased approach to analyzing and building system using cycle that is specific to user activity [21]. System Development Life Cycle (SDLC) is also a center for the development of efficient information system [22]. System Development Life Cycle (SDLC) is a process to understand the stages of how information system can support need, design system and build system [23]. These stages include:

1. Stage of planning (System Planning)

The stages of system planning include:

a. Data Master (Patient data, Doctor data, Drug data)

b. Patient Service Data Transaction

c. Reports needed

2. Design Stage (System

Design) 
The system design that the researcher would make in preparing this junal consists of:

1) Flowchart

2) The system being used

3) Proposed Context

4) Technology Stage

5) Data Report

The following is an overview of the System Development Life Cycle (SDLC):

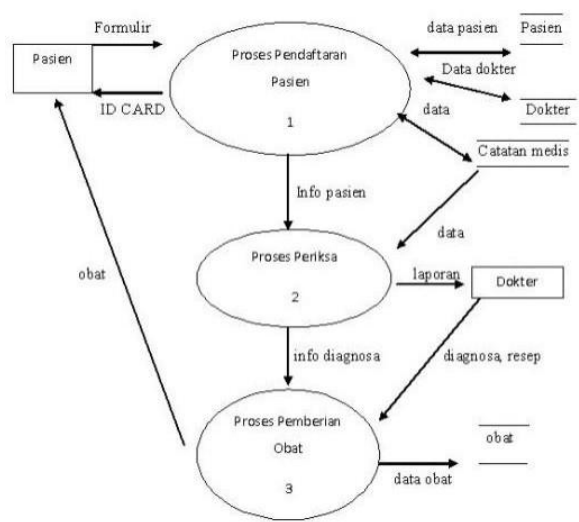

Figure 1. System Development Life Cycle (SDLC)

\section{SYSTEM DESIGN AND IMPLEMENTATION}

\subsection{Problem Analysis}

In general, the system at the Public Health Center used is a manual system. Manual system is not yet using a computerized system, registration is still using the system calls by officer, long queues, and the presentation of report is still using human assistance so there are still many errors and the data is not accurate.

In this multiuser-based Public Health Center service information system has two paths that can be accessed by users (patients and Public Health Center staff / server ), the first path is used to serve patient, including: patient registration, knowing the doctor's name and schedule, payment transaction, while the second pathway is for public health center staff / server to more easily access all information about patient needs because the data that has been inputted by patient can be directly accessed by public health center staff / server.

Existing data is immediately processed quickly and accurately, and incoming data can be seen or stored, so if you need data from the previous day and using this system information can be obtained easily and practically.

\subsection{ERD}

Entity Relationship Diagram is a relationship between table in a database, the following is ERD Patient Service Information System:

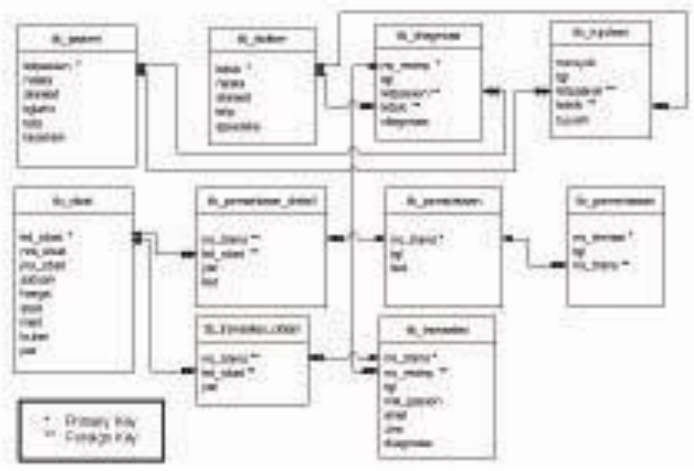

Figure 2. Entity Relationship Diagram

\subsection{IMPLEMENTATION}

\subsubsection{Flowchart}

Multiuser Based Patient Information System can be clarified by using a Flowchart consisting of a Car Entry flowchart and Car out flowchart.

a. Car Entry Flowchart is a description of the data that flows on the process of patient registration. It can be seen in Figure 3.

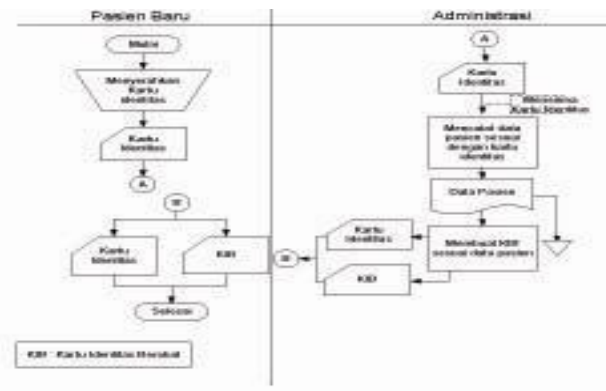

Figure 3. Entry Flowchart

b. Car Out Flowchart is a description of the data that flows on the process that occurs during a payment transaction. See Figure 4.

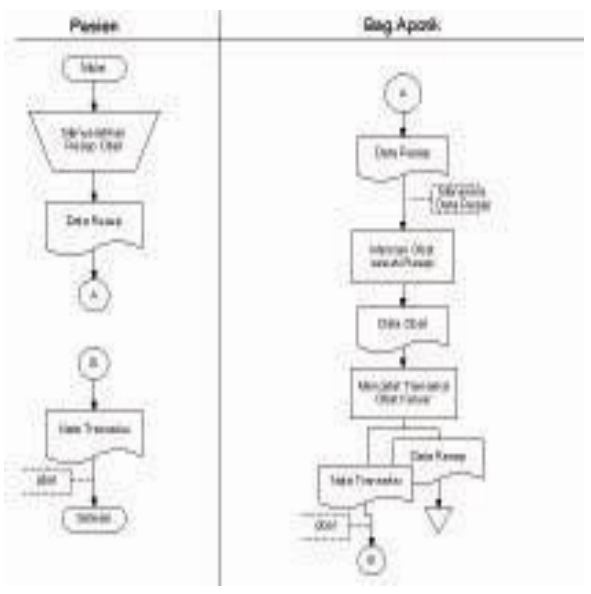

Figure 4. Car Out Flowchart 


\section{Multi User-Based Patient Service Information System in Public Health Center}

\subsubsection{System Being Used}

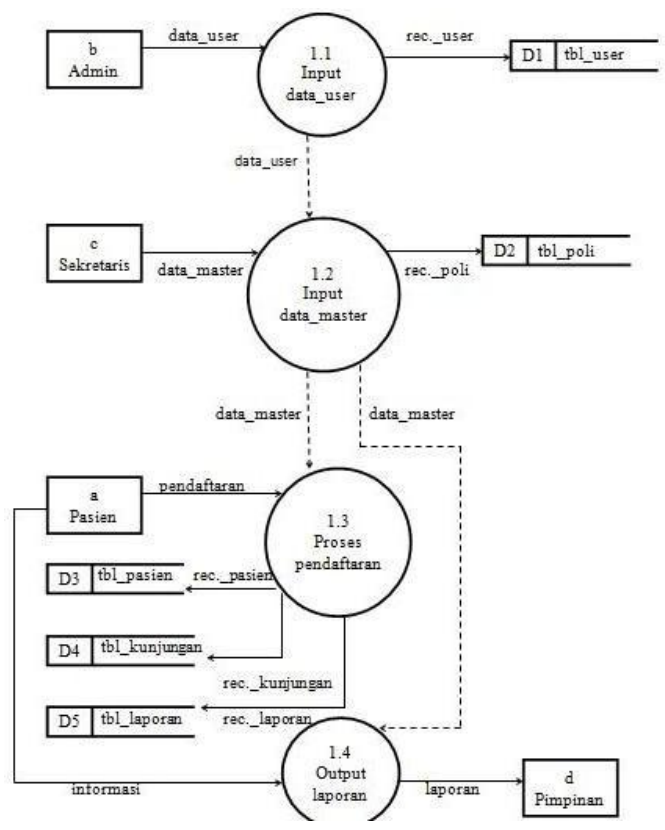

Figure 5. The system being used

\subsubsection{Context Diagram}

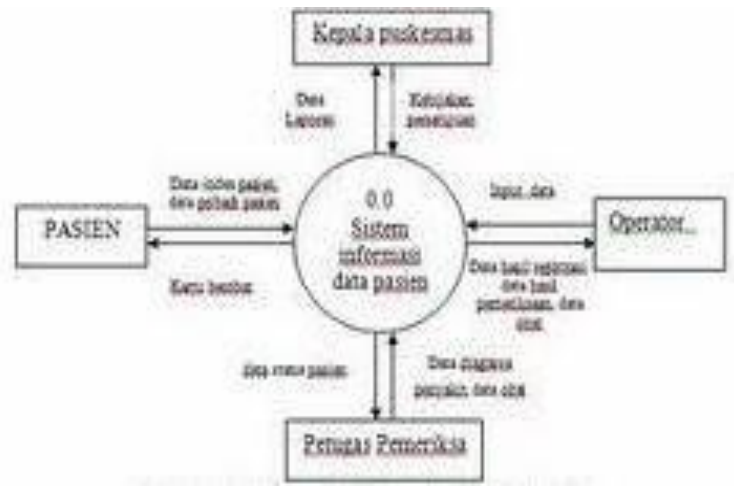

Figure 6. Proposed Context Diagram

\subsubsection{Algorithm or Program}

In this design, the main menu will be shown, namely: The home menu which contained data and transaction inputs.

\subsubsection{Home Page Display}

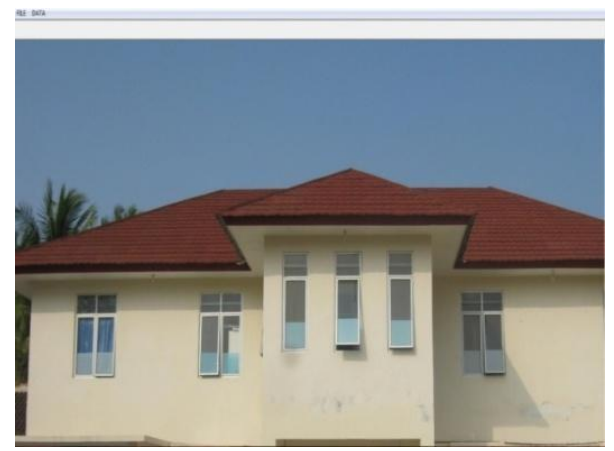

Figure 7. Home Page Display
Patient Registration Form

The following is the electronic form for patient registration, patient registered using the following form, see figure 8 .

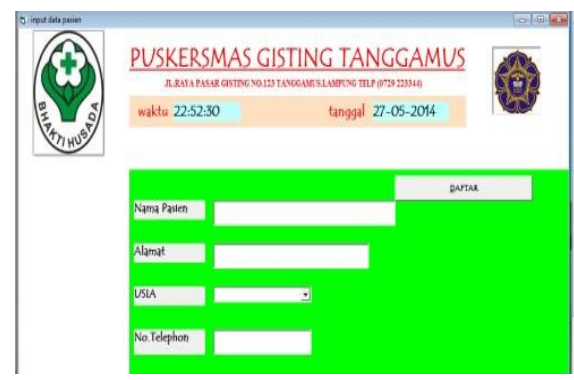

Figure 8. Patient Form Display

\subsubsection{PATIENT DATA InPUT}

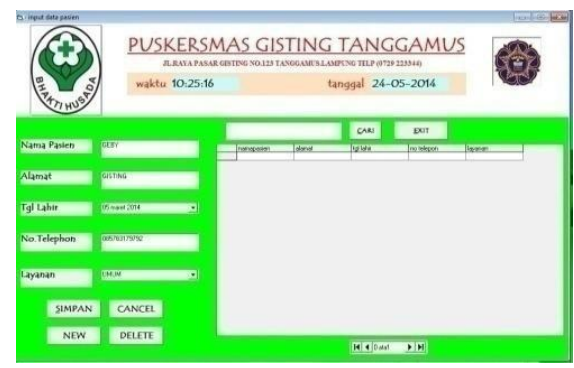

Figure 9. Display of Patient Data

\subsubsection{DOCTOR DATA INPUT}

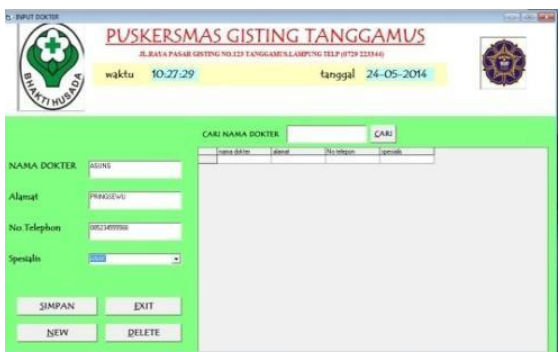

Figure 10. Doctor Data Input

\subsubsection{DRUG DATA INPUT}

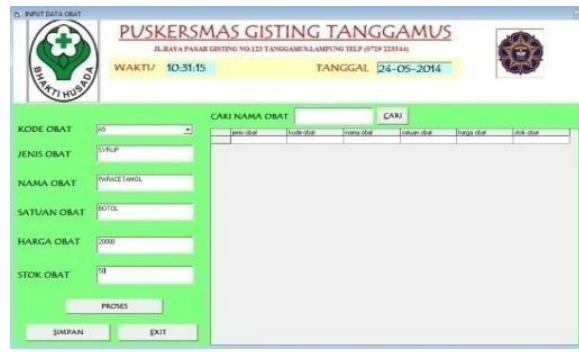

Figure 11. Drug Data Input Payment Transaction 


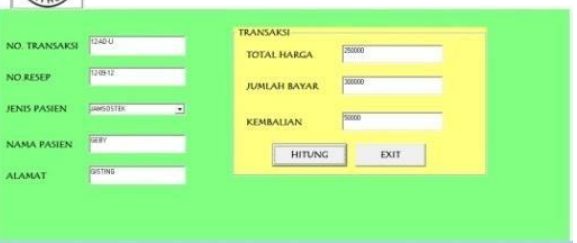

Figure 12. Payment Transaction

\subsubsection{PATIENT DATA REPORT}

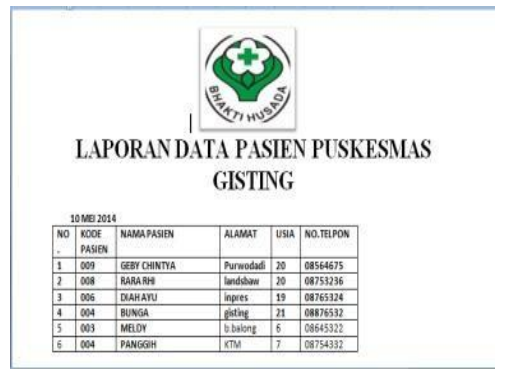

Figure 13. Patient Data Report

\subsubsection{DOCTOR DATA REPORT}

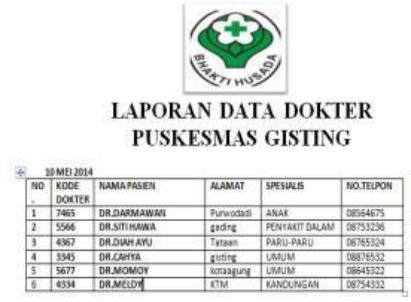

Figure 14. Doctor Data Report

4.3.1.7 DRUG DATA REPORT

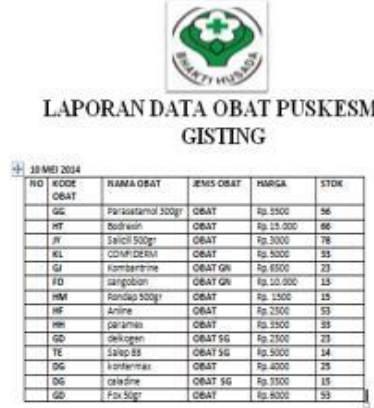

Figure 15. Drug Data Report

\subsubsection{PATIENT Visit REPORT}

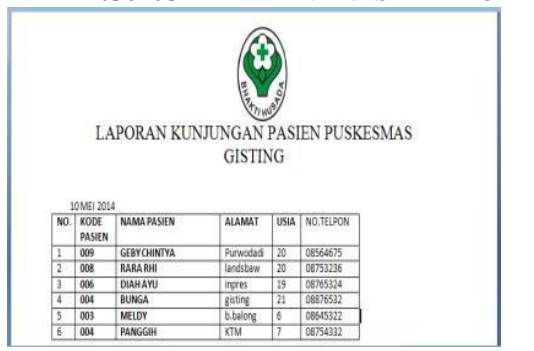

Figure 16. Patient Visit Report

\section{CONCLUSION/ RECOMMENDATIONS}

\subsection{Conclusion}

1. Inputs used include: Patient Data Input, Doctor Data Input, and Drug Data Input.

2. Reports produced: Patient Data Report, Doctor Data Report, Drug Data Report, Patient Visit Report.

3. Database used are tb_patient, tb_doctor, tb_drug, tb_transaction_detail.

4. Facilities contained in this application: Login user and password

\subsection{Suggestion}

1. It is expected to have further development of this Patient Service Information System based on client server, so it becomes a system with broader scope.

2. For further development, this program should be able to add more process such as staff data processing.

\section{REFERENCES}

1. Maseleno, A., Hardaker, G., Sabani, N., \& Suhaili, N. (2016). Data on multicultural education and diagnostic information profiling: Culture, learning styles and creativity. Data in brief, 9, 1048.

2. Maseleno, A., Huda, M., Jasmi, K. A., Basiron, B., Mustari, I., Don, A G., \& bin Ahmad, R. (2019). Hau-Kashyap approach for student's level of expertise. Egyptian Informatics Journal, 20(1), 27-32.

3. Maseleno, A., Huda, M., Siregar, M., Ahmad, R., Hehsan, A., Haron, Z., ... \& Jasmi, K. A. (2017). Combining the previous measure of evidence to educational entrance examination. Journal of Artificial Intelligence, 10(3), 85-90.

4. Chienwattanasook, K. \& Jermsittiparsert, K. 2019. "Impact of Entrepreneur Education on Entrepreneurial Self-Employment: A Case Study from Thailand.” Polish Journal of Management Studies 19 (1): 106-116.

5. Jermsittiparsert, K., Sutduean, J., Sriyakul, T., \& Khumboon, R. 2019. "The Role of Customer Responsiveness in Improving the External Performance of an Agile Supply Chain." Polish Journal of Management Studies 19 (2): 206-217.

6. Jermsittiparsert, K., Sutduean, J., \& Sriyakul, T. 2019. "Effect of Service Innovation and Market Intelligence on Supply Chain Performance in Indonesian Fishing Industry." Industrial Engineering \& Management Systems 18 (3): 408-417.

7. Jermsittiparsert, K., Namdej, P., \& Somjai, S. 2019. "Green Supply Chain Practices and Sustainable Performance: Moderating Role of Total Quality Management Practices in Electronic Industry of Thailand.” International Journal of Supply Chain Management 8 (3) 33-46.

8. Somjai, S. \& Jermsittiparsert, K. 2019. "The Trade-off between Cost and Environmental Performance in the Presence of Sustainable Supply Chain." International Journal of Supply Chain Management 8 (4): 237-247.

9. Jermsittiparsert, K. \& Sawasdee, A. 2012. "Formal Education for Non-Thai or Undocumented Person in Thailand amidst the Challenge of Nationalism and Transnationalism: A Case Study of Wat Sirimongkhol School, Samut Sakhon Province." Kasetsart Journal - Social Sciences 33 (2): 203-213.

10. Chienwattanasook, K., Wattanapongphasuk, W., Prianto, A., \& Jermsittiparsert, K. 2019. "Corporate Entrepreneurship and Business Performance of Logistic Companies in Indonesia." Industrial Engineering \& Management Systems 18 (3): 538-547.

11. Dawabsheh, M., Hussein, A., \& Jermsittiparsert, K. 2019. "The Triangular Relationship between TQM, Organizational Excellence and Organizational Performance: A Case of Arab American University Palestine.” Management Science Letters 9 (6): 921-932.

12. Jermsittiparsert, K., Siam, M., Issa, M., Ahmed, U., \& Pahi, M. 2019. "Do Consumers Expect Companies to Be Socially Responsible? The Impact of Corporate Social Responsibility on Buying Behavior." Uncertain Supply Chain Management 7 (4): 741-752.

Published By: 
13. Syazali, M., Putra, F., Rinaldi, A., Utami, L., Widayanti, Umam, R., \& Jermsittiparsert, K. 2019. "Partial Correlation Analysis Using Multiple Linear Regression: Impact on Business Environment of Digital Marketing Interest in the Era of Industrial Revolution 4.0." Management Science Letters 9 (11): 1875-1886.

14. Sae-Lim, P. \& Jermsittiparsert, K. 2019. "Is the Fourth Industrial Revolution a Panacea? Risks toward the Fourth Industrial Revolution: Evidence in the Thai Economy." International Journal of Innovation, Creativity and Change 5 (2): 732-752.

15. Chatchawanchanchanakij, P., Arpornpisal, C., \& Jermsittiparsert, K. 2019. "The Role of Corporate Governance in Creating a Capable Supply Chain: A Case of Indonesian Tin Industry." International Journal of Supply Chain Management 8 (3): 854-864.

16. Hartinah, S., Suharso, P., Umam, R., Syazali, M., Lestari, B., Roslina, R., \& Jermsittiparsert, K. 2020. "Teacher's Performance Management: The Role of Principal's Leadership, Work Environment and Motivation in Tegal City, Indonesia." Management Science Letters 10 (1): 235-246.

17. Haseeb, M., Hussain, H., Slusarczyk, B., \& Jermsittiparsert, K. 2019. "Industry 4.0: A Solution towards Technology Challenges of Sustainable Business Performance.” Social Sciences 8 (5): 184.

18. Haseeb, M., Hussain, H., Kot, S., Androniceanu, A., \& Jermsittiparsert, K. 2019. "Role of Social and Technological Challenges in Achieving a Sustainable Competitive Advantage and Sustainable Business Performance." Sustainability 11 (14): 3811.

19. Haseeb, M., Kot, S., Hussain, H., \& Jermsittiparsert, K. 2019. "Impact of Economic Growth, Environmental Pollution, and Energy Consumption on Health Expenditure and R and D Expenditure of ASEAN Countries." Energies 12 (19): 3598.

20. Huda, S., Tsani, I., Syazali, M., Umam, R., \& Jermsittiparsert, K. 2020. "The Management of Educational System Using Three Law Auguste Comte: A Case of Islamic Schools." Management Science Letters 10 (3) (In press), DOI: 10.5267/j.msl.2019.9.018.

21. Usak, M., Kubiatko, M., Shabbir, M., Dudnik, O., Jermsittiparsert, K., \& Rajabion, L. 2019. "Health Care Service Delivery Based on the Internet of Things: A Systematic and Comprehensive Study." International Journal of Communication Systems 32 (14): e4179.

22. Jermsittiparsert, K., Ambarita, D., Mihardjo, L., \& Ghani, E. 2019. "Risk-Return through Financial Ratios as Determinants of Stock Price: A Study from ASEAN Region." Journal of Security and Sustainability Issues 9 (1): 199-210.

23. Thabhiranrak, T. \& Jermsittiparsert, K. 2019. "Towards Sustainable Functioning of Organization: Women Empowernment and Corporate Management Culture.” Journal of Security and Sustainability Issues 9 (1): 321-332. 